\title{
Die zwölfte Rippe
}

\section{Iris Ritzmann}

Prof. Dr. med. et lic. phil., Mitglied der Redaktion Medizingeschichte

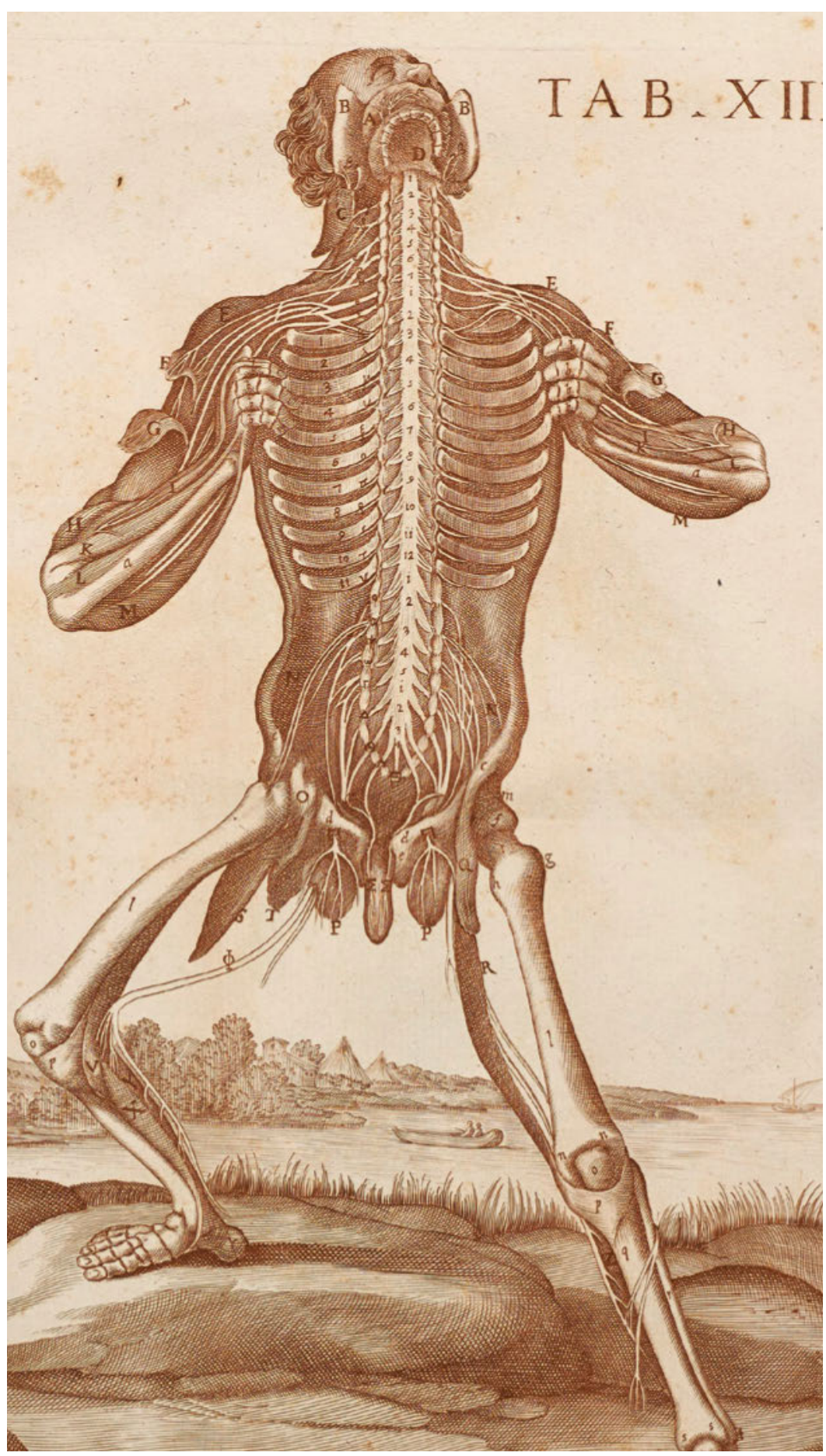

Pietro Berrettini da Cortona, herausgegeben von Francesco Petraglia: Tabulae Anatomicae, 2. Ausg. Rom 1788, Tab. XIIII, S. 131, Sammlung Dr. Franz Käppeli.
Erschuf Gott den Menschen aus Lehm? Oder war es doch die Rippe Adams, aus der Gott Eva schnitzte? Besassen Adam und Eva einen Bauchnabel, obschon sie keine Geburt erlebten? Gehört Schönheit stets zum menschlichen Körper, da der Mensch als Gottes Ebenbild erschaffen wurde? Solche und ähnliche Fragen beschäftigten in der Vormoderne nicht nur Theologen. Auch die medizinische Wahrnehmung und Beschreibung des menschlichen Körpers durften in Zeiten religiöser Zensurbehörden den kirchlichen Vorgaben nicht widersprechen. So bestätigt der Blick in einen Anatomieatlas, dass der männliche Körper lediglich elf Rippen aufweist. Die Rippen wurden sogar gut sichtbar durchnummeriert, um ja keine Zweifel an ihrer Zahl aufkommen zu lassen.

Das Bild ist Teil eines anatomischen Bildzyklus, der vermutlich in den Jahren um 1618 als Erstlingswerk des bekannten Barockarchitekten Pietro Berrettini, genannt Cortona, entstand. Der junge Cortona begleitete den Anatomen Giovanni Maria Castellani als wissenschaftlicher Zeichner. Da Castellani neben seiner Professur auch die Leitung des Ospedale Santo Spirito innehatte, stand ihm die Zerlegung der verstorbenen Spitalinsassen zu. Die Zeichnungen, auf denen Cortona die Toten als lebendige Präparate mit Symbolen der Vergänglichkeit oder vor Landschaften inszenierte, wurden zwar noch in Kupfer gestochen, doch erst über hundert Jahre später, in einer Zeit akuten Leichenmangels, veröffentlicht. Obschon sich das Fach Anatomie inzwischen gewandelt hatte, riefen Cortonas grausig-schöne Bilder eine derart grosse Faszination hervor, dass der römische Arzt und Philosoph Francesco Petraglia sie wenige Jahrzehnte später gleich nochmals in einem anatomischen Atlas herausgab. Mit dieser Zweitauflage fand der anatomische Kunstatlas als Buchtypus seinen glanzvollen Abschluss. Die naturwissenschaftliche Orientierung der modernen Medizin brachte es mit sich, dass die emotional aufgeladenen Inszenierungen von nüchternen Illustrationen abgelöst wurden. Und die zwölfte Rippe tauchte auf. Allerdings zeigen auch moderne Anatomiebücher kaum je reale Leichenbilder, sondern stark idealisierte, meist männliche Körper von beinahe göttlicher Schönheit.

Museum für medizinhistorische Bücher Muri (mmbm.ch) 